\title{
Antifungal activity of silver nanoparticles synthesized using Citrus sinensis peel extract against fungal phytopathogens isolated from diseased tomato (Solanum lycopersicum L.)
}

Onyemaechi H. Obiazikwor ${ }^{1 *}$ and Hakeem 0. Shittu ${ }^{1}$

${ }^{1}$ Department of Plant Biology and Biotechnology, Faculty of Life Sciences, University of Benin, Benin City, Edo State, Nigeria.

${ }^{*}$ Correspondent Author Email: onyemaechi.obiazikwor@uniben.edu
Nanoparticles exhibit unusual physical, chemical and biological activity due to their reduced small sizes and they are applied in various disciplines including engineering, medicine and agriculture. The current study was carried out to investigate the antifungal activity of silver nanoparticles synthesized using Citrus sinensis peel extract against fungal phytopathogens isolated from diseased tomato. Silver nanoparticles were synthesized using Citrus sinensis peel extract and the formation of nanoparticles was monitored using spectrophotometry. The isolated fungal phytopathogens include Irenopsis, Diaporthe and Sphaerosporium spp. These phytopathogens were grown on potato dextrose agar supplemented with different concentrations of Citrus peel extract, silver nitrate solution or silver nanoparticles. Mycelia growth was recorded at 2 days' interval for 8 days. From the results obtained, $100 \%$ concentration of silver nanoparticles offered the highest antifungal activity with an inhibition rate of 82, 46 and $57 \%$ recorded for Irenopsis, Diaporthe and Sphaerosporium species, respectively after 8 days of culture initiation. The findings of this research indicated that silver nanoparticles were effective in controlling fungal isolates. Further studies should be carried out to investigate the mode of action and the use of silver nanoparticles in managing phytopathogens in crop plants, thereby ensuring food security.

Key words: Antimicrobial, crop plants, fungi, food security.

\section{INTRODUCTION}

There is an increasing demand for food production due to the fast growing human population; therefore, food security has become a global issue. It is estimated that by 2050 , an additional $70 \%$ food production is needed to fulfill the demand of the population (Godfray et al., 2010). Phytopathogens such as bacteria, viruses and fungi cause lots of damages when they infect crop plants, thereby leading to low plant productivity (Savay et al., 2012). The protection of crop plants against diseases therefore, has a major role to play in meeting the food demand of the ever growing human population. Different management strategies such as physical, cultural, chemical and biological methods have been adopted for the management of plant diseases (Agrios, 2005). These strategies rely on control methods that either eradicate or reduce the pathogen inoculum. The uses of such disease control measures are associated with several limitations; and each pathogen has a control strategy that works best for its control. Furthermore, there is an increasing microbial resistance against antibiotics and development of resistant strains (Agrios, 2005). It is therefore imperative to develop a novel, ecofriendly and very effective control strategy that can target multiple pathogens in crop plants. Nanoparticles have been used in this regard to control several human pathogens, but little studies have been done on their use in controlling phytopathogens (Balakumaran et al., 2016). 
Substances in structure ranging from approximately 1-100 $\mathrm{nm}$ in size are referred to as nanoparticles and the modern research concern with the synthesis, strategy and manipulation of nanoparticles is known as nanotechnology (Ahmed et al., 2016). Nanoparticles exhibit unusual physical, chemical and biological activity due to their reduced small sizes (Rao and Paria, 2013; Mariselvan et al., 2014), thereby making them suitable for many applications. Silver nanoparticles are of immense interests among all the common nanoparticles. This is because they possess unique properties including good conductivity, chemical stability, catalytic and most imperative, antimicrobial activities (Ahmed et al., 2016). Silver nanoparticles are now incorporated into several consumer products such as clothing, cosmetics and medicine because of their antimicrobial and medicinal properties (Ahmed et al., 2016). Physical, chemical and biological methods are employed in the synthesis of nanoparticles (Panigrahi, 2013). There is advancement of biological method (green synthesis) over physical and chemical methods, because it is ecofriendly, cost effective and it can easily be scaled up for large production (Ahmed et al., 2016). The biological method of nanoparticle synthesis involves the use of living organisms such as bacteria, fungi and plants (Panigrahi, 2013). The use of plant extracts in this regard offers additional advantages over microorganisms such as ease of maintenance and reduction of cost of isolating microorganisms (Ahmed et al., 2016). Phytopathogens cause lots of damages and loss when they infect crop plants such as tomato.

The commercial tomato is one of the most popular and widely eaten vegetables in the world. In the last four decades, global production has increased by around $300 \%$ (Heuvelink, 2005). More than 120 million metric tons are grown annually (Kimura and Sinha, 2008). Tomato is mostly famous for its culinary, industrial and ornamental values; however, it also possesses several characteristics that allow it to serve as a suitable well-established model plant for the study of many biological processes and in particular for genetic and phytopathological studies (Shittu and Robb, 2011). Tomato is a susceptible host plant to several economically important phytopathogens. The aim of this preliminary study was to investigate the in vitro antifungal activity of silver nanoparticles synthesized using Citrus sinensis peel extract against fungal phytopathogens isolated from diseased tomato.

\section{MATERIALS AND METHODS}

\section{Materials used}

The diseased tomato plants used for this study were collected from a farmland in Ovia North-East Local Government Area, Benin City, Edo State. The fresh orange fruits used for the synthesis of silver nanoparticles were obtained from an orange tree growing in an open field at Ishior Quarter, Benin City, Edo State, Nigeria.

\section{Isolation of phytopathogens from diseased tomato plants}

The diseased tomato samples were prepared by teasing the plant parts (leaves and roots) used into smaller pieces, followed by surface sterilization with alcohol to remove surface contaminants. The pour plate method of inoculation technique was used for the isolation of phytopathogens associated with the diseased tomato samples. Potato dextrose agar (PDA) was used for the isolation of fungal isolates and the cultures were incubated at room temperature $\left(28 \pm 2{ }^{\circ} \mathrm{C}\right)$ for 72 hours.

\section{Characterization and identification of isolates}

The fungal isolates from the diseased tomato samples were characterized and identified using macroscopy and microscopy. The morphological features were observed and described. The isolates were also observed on the microscope after staining with lactophenol. A drop of lactophenol blue stain was released on a clean sterile glass slide and after this a germ-free inoculating wire loop was used to pick the mycelium unto the glass slide from the culture. The mycelium was teased and uniformly spread on the slide. The slide was then covered with a cover slip and left for some seconds before observation at $\mathrm{x} 40$ under the microscope. This was then compared with a laboratory manual for fungal identification (Peipenbring, 2015).

\section{Synthesis and characterization of nanoparticles}

Silver nanoparticles were synthesized according to the method described by Kaviya et al. (2011). Citrus sinensis peel extract was prepared by washing fresh pills with double distilled water, followed by cutting into smaller pieces. About 20 grams of the peels were weighed and transferred into a $250 \mathrm{ml}$ beaker containing $200 \mathrm{ml}$ of sterile distilled water and the mixture was then boiled for 2 $\min$. The peels were removed by filtering the extract before using it. An aliquot of $3 \mathrm{ml}$ of orange peel extract was added to $40 \mathrm{ml}$ of $1 \mathrm{mM}$ aqueous solution of $\mathrm{AgNO}_{3}$. The resulting solution was mixed thoroughly and incubated for $30 \mathrm{~min}$ at room temperature $\left(28 \pm 2{ }^{\circ} \mathrm{C}\right)$. A brownish colour appearance indicated the formation of silver nanoparticles (Figure 1).

Characterization of the synthesized nanoparticles was done using spectrophotometric analysis. The bioreduction of $\mathrm{Ag}^{+}$in solution was monitored using UV-visible spectrophotometer. This was carried out by measuring the absorbance at regular intervals $(1,24$ and 48 hours after synthesis) within the wavelength of 300-500 nm.

\section{Investigation of the antifungal activities of silver nanoparticles on test phytopathogens}

The antifungal activity of Citrus peel extract, silver nitrate solution and silver nanoparticles on the fungal isolates was carried out using the food poisoning method. Three 


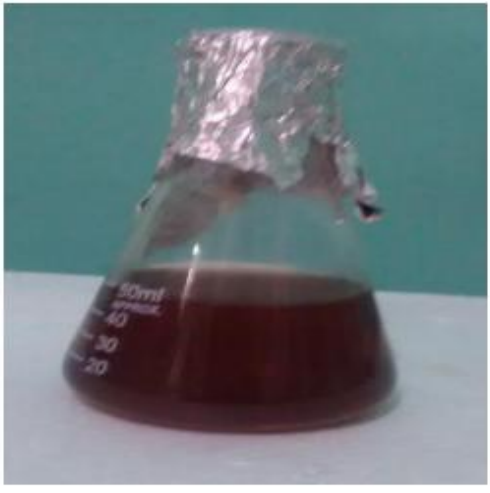

a

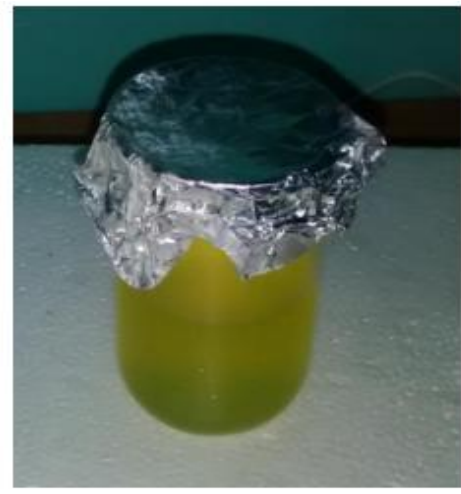

b

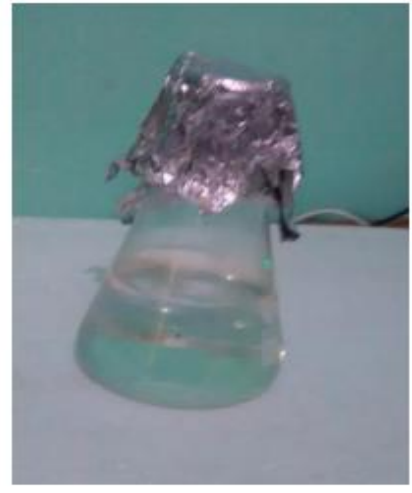

C

Figure 1: Solutions used for antimicrobial activity testing. (a) Silver nanoparticles (b) Citrus peel extract (c) Silver nitrate solution

different concentrations corresponding to 100,50 and $0 \%$ of silver nanoparticle were prepared. The $100 \%$ silver nanoparticle was taken to be the stock solution while the $50 \%$ was prepared by dispensing $50 \mathrm{ml}$ of sterile distilled water into $50 \mathrm{ml}$ of silver nanoparticle solution. The $0 \%$ was the control without nanoparticle. An aliquot of $1 \mathrm{ml}$ of the nanoparticles for the different concentrations was added to $9 \mathrm{ml}$ of PDA after pouring onto Petri dishes under sterile conditions. This was then shaken carefully and allowed to gel. After solidifying, the medium was inoculated by picking a culture plug of the fungal culture and placing it at the center and the cultures were incubated for two days. The fungal mycelia growth was measured for a period of 8 days. The same process was repeated for the Citrus peel extract and the different concentrations, 0, 50 and $100 \%$ were prepared accordingly. In the same manner, different concentrations, 0,50 and $100 \%$ of silver nitrate solution were prepared accordingly, using $1 \mathrm{mM}$ aqueous solution of $\mathrm{AgNO}_{3}$ as the stock $(100 \%)$. The rate of inhibition of fungal growth by the nanoparticle treatment was calculated according to Mahdizadeh et al. (2015).

\section{Statistical analysis}

Each treatment was in three replicates and results were presented as mean \pm standard error. The data obtained were subjected to parametric and descriptive statistics using the Statistical Package for the Social Sciences (SPSS) version 20 software. An alpha value of 0.05 was used as the level of significance. Post-hoc analysis using the Duncan multiple range test was also carried out to determine which mean was significantly different from each other.

\section{RESULTS}

Silver nanoparticles were synthesized using Citrus peel extract. The biosynthesized silver nanoparticles were subjected to spectrophotometric analysis at different wavelengths after 1, 24 and 48 hours of synthesis (Figure 2). The absorbance values were observed to increase with increasing time (in hours) after synthesis. The maximum absorption values were recorded around the wavelength of $415-450 \mathrm{~nm}$. In this study, Irenopsis, Diaporthe and Sphaerosporium spp. were the fungal pathogens isolated from diseased tomato. The results obtained for the effects of Citrus peel extract (CPE), silver nitrate solution (SNS) or silver nanoparticles (SNP) when used for media supplementation on the mycelia growth of Irenopsis sp. are shown in Table 1. Growth was observed to increase with increasing day of incubation. At the $8^{\text {th }}$ day, the highest mycelia growth was recorded for all the controls $(0 \%$ treatment) for the CPE, SNS and SNP with values of $8.50 \pm 0.00,8.35 \pm 0.15$ and $8.50 \pm 0.00$, respectively. There were no significant differences between mycelia growth of Irenopsis sp. subjected to $0 \%, 50 \%$ and $100 \% \mathrm{CPE}$ treatment throughout the incubation period (Figure 3; at the $6^{\text {th }}$ day of incubation). For the SNS, there was slight reduction in growth at $50 \%(7.80 \pm 0.20)$ and $100 \%$ $(5.95 \pm 0.05)$ at the $8^{\text {th }}$ day of incubation. Mycelia growth was observed to reduce significantly $(\mathrm{p}<0.05)$ with SNP treatment at the $8^{\text {th }}$ day of incubation with values of $2.20 \pm 0.20$ for $50 \%$ treatment to $1.50 \pm 0.00$ for $100 \%$ treatment (Figure 4 and Table 1).

A similar observation was made when Diaporthe sp. was inoculated onto a PDA, supplemented with the test solutions (CPE, SNS or SNP). The results (Table 2) obtained showed that the growth of the pathogen was not inhibited in the CPE treatment throughout the incubation period. Some level of inhibition in mycelia growth was observed in the SNS treatment. There was a significant $(\mathrm{p}<0.05)$ difference in mycelia growth reduction in the SNP treatment from $4.10 \pm 0.40$ to $2.20 \pm 0.40$ to $1.75 \pm 0.05$ for the $0 \%, 50 \%$ and $100 \%$ treatment, respectively at the $6^{\text {th }}$ day of incubation (Figure 5). Table 3 showed the effect of the test solutions, each on the mycelia growth of Spaerosporium 


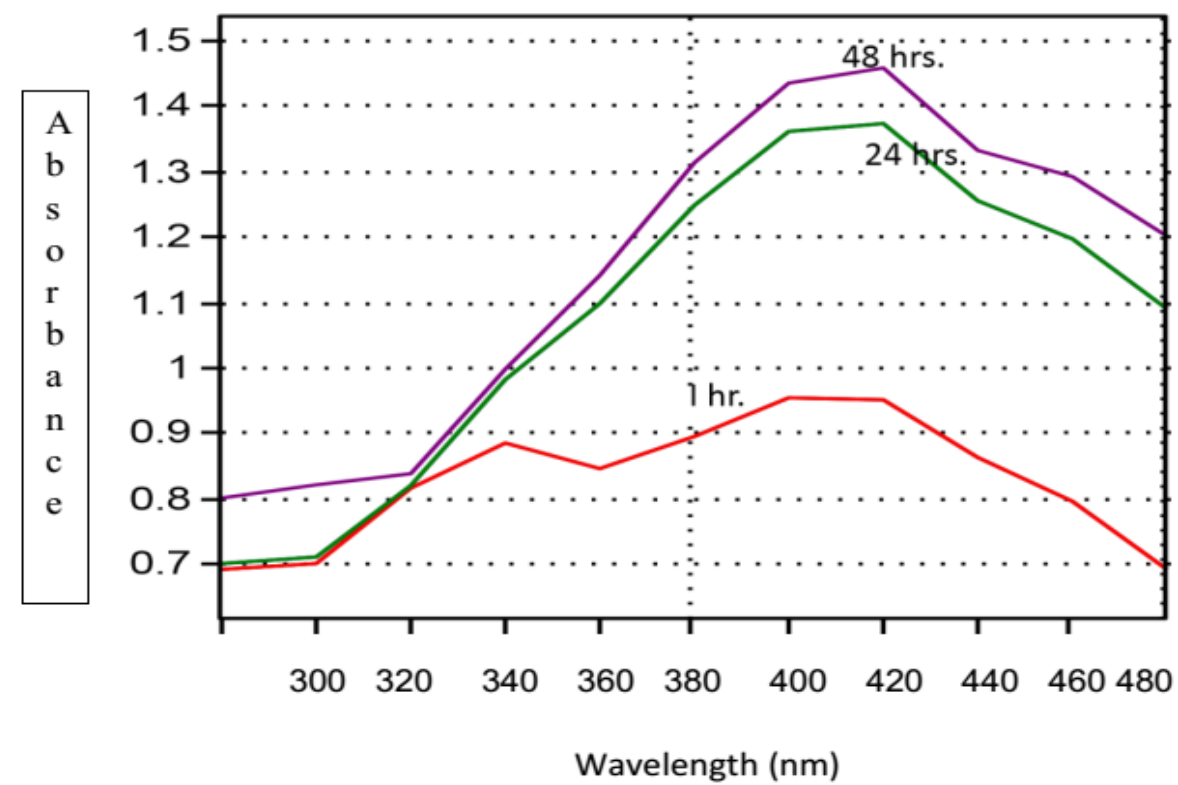

Figure 2: Comparison of Absorbance values of biologically synthesized silver nanoparticles measured 1, 24 and 48 hours after synthesis

Legend: Red $=$ Absorbance after one hour,

Green $=$ Absorbance after 24 hours,

Purple = Absorbance after 48 hours.

Table 1. Effects of Citrus peel extract, silver nitrate solution and silver nanoparticles on the mycelial growth of Irenopsis species

\begin{tabular}{|c|c|c|c|c|c|c|c|c|c|c|c|c|}
\hline \multirow{2}{*}{$\begin{array}{l}\text { Conc. } \\
(\%)\end{array}$} & \multicolumn{3}{|c|}{2 days } & \multicolumn{3}{|c|}{4 days } & \multicolumn{3}{|c|}{6 days } & \multicolumn{3}{|c|}{8 days } \\
\hline & CPE (cm) & SNS (cm) & SNP (cm) & CPE (cm) & SNS (cm) & SNP (cm) & CPE (cm) & SNS (cm) & SNP (cm) & CPE (cm) & SNS (cm) & SNP (cm) \\
\hline 0 & $4.70 \mathrm{a} \pm 0.10$ & $4.60^{b} \pm 0.10$ & $4.65^{b} \pm 0.15$ & $7.70^{\mathrm{a}} \pm 0.10$ & $7.30^{\mathrm{b}} \pm 0.30$ & $7.65^{b} \pm 0.15$ & $8.00^{\mathrm{a}} \pm 0.10$ & $8.10^{b} \pm 0.00$ & $8.50^{c} \pm 0.00$ & $8.50^{\mathrm{a}} \pm 0.00$ & $8.35^{b} \pm 0.15$ & $8.50^{c} \pm 0.00$ \\
\hline 50 & $4.65^{\mathrm{a} \pm 0.15}$ & $3.95^{\mathrm{ab}} \pm 0.05$ & $0.70^{a} \pm 0.10$ & $7.60 \mathrm{a} \pm 0.10$ & $6.95^{\mathrm{ab}} \pm 0.05$ & $0.75^{\mathrm{a} \pm 0.15}$ & $8.50^{\mathrm{b}} \pm 0.00$ & $7.60^{\mathrm{b}} \pm 0.10$ & $0.90^{\mathrm{b}} \pm 0.00$ & $8.50^{\mathrm{a}} \pm 0.00$ & $7.80^{\mathrm{b}} \pm 0.20$ & $2.20^{\mathrm{b}} \pm 0.20$ \\
\hline 100 & $4.60^{\mathrm{a} \pm 0.20}$ & $3.75^{\mathrm{a} \pm 0.25}$ & $0.60 \mathrm{a} \pm 0.10$ & $7.60^{\mathrm{a}} \pm 0.10$ & $6.25^{\mathrm{a}} \pm 0.25$ & $0.65^{a} \pm 0.15$ & $8.50^{\mathrm{b}} \pm 0.00$ & $6.80^{\mathrm{a} \pm 0.20}$ & $0.65^{\mathrm{a}} \pm 0.05$ & $8.50^{\mathrm{a}} \pm 0.00$ & $5.95^{\mathrm{a} \pm 0.05}$ & $1.50^{\mathrm{a} \pm 0.00}$ \\
\hline
\end{tabular}

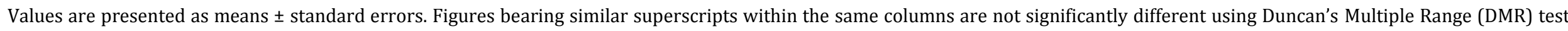
at 0.05 level of significance. CPE: Citrus peel extract; SNS: Silver nitrate solution; SNP: Silver nanoparticles.

sp. A reduction in mycelia growth was observed in the $100 \%$ SNP treatment, as values decreased from
$2.20 \pm 0.40$ at $6^{\text {th }}$ day of incubation (Figure 6) to $1.75 \pm 0.05$ at $8^{\text {th }}$ day of incubation. The inhibition rate of 50 and $100 \%$ silver nanoparticles on mycelia growth of the test fungal organisms after $8^{\text {th }}$ day of 

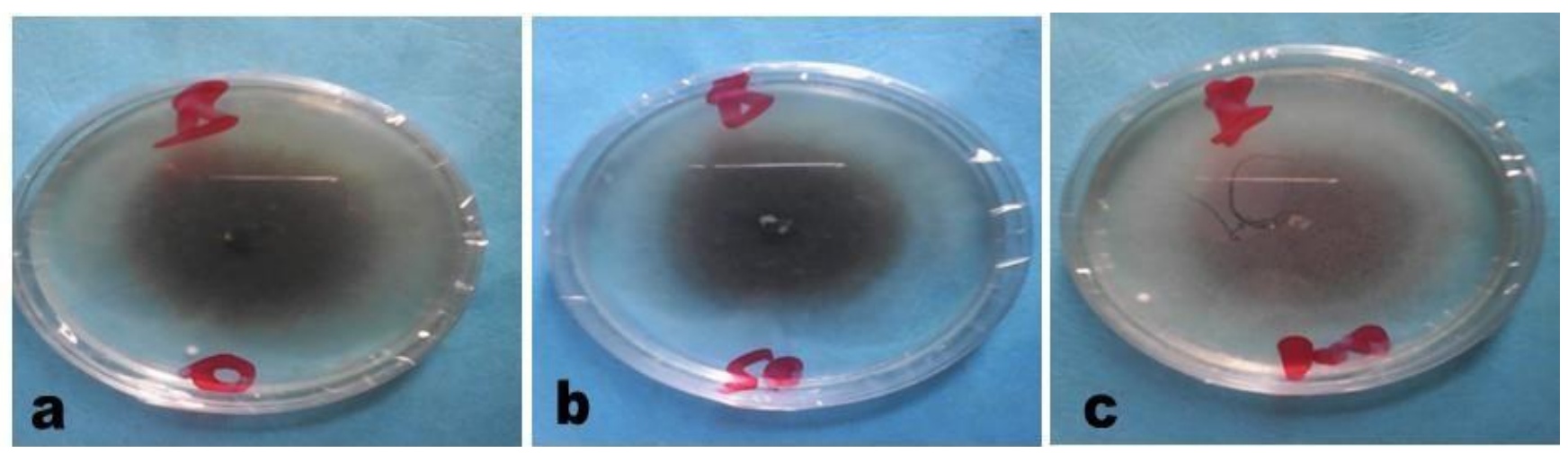

Figure 3: Effects of Citrus peel extract on the mycelia growth of Irenopsis sp. grown on PDA at room temperature after 6 days of incubation. a: Control ( $0 \%$ concentration of Citrus peel extract); b: $50 \%$ Citrus peel extract; c: $100 \%$ Citrus peel extract

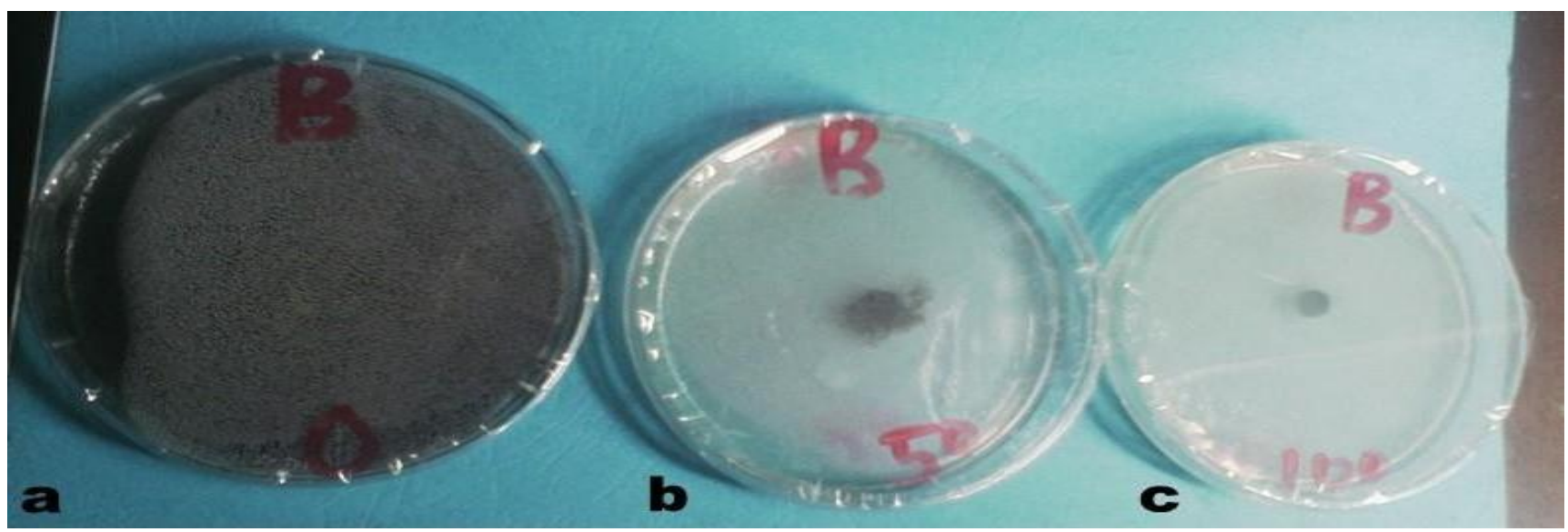

Figure 4: Effects of silver nanoparticles on the mycelia growth of Irenopsis sp. grown on PDA at room temperature after 8 days of incubation. a: Control ( $0 \%$ concentration of silver nanoparticles); b: $50 \%$ silver nanoparticles; c: $100 \%$ silver nanoparticles

incubation is shown in Figure 7. Hundred percent SNP treatment was most effective on Irenopsis sp.

(82\% inhibition) when compared to the Diaporthe sp. (46\% inhibition) and Sphaerosporium sp. (57\%

inhibition).

\section{DISCUSSION}

Silver nanoparticles (SNP) were biologically synthesized using Citrus peel extracts (CPE) and spectrophotometric analysis was carried out. The absorbance values of the SNP after 1, 24 and 48 hour of synthesis (Figure 2) increased in the various time intervals and the peaks were noticed around $415-450 \mathrm{~nm}$ corresponding to the surface plasmon resonance of SNP. The observation indicated that silver ions were reduced extracellularly. The presence of phytochemicals such as terpenoids, flavones, ketones, aldehydes, amines and carboxylic acids in plants have been suggested to be responsible for this plant-mediated reduction of silver ions (Panigrahi, 2013). Several plants such as Ocimum teniflorum, Solanum tricobatum, Syzygium cumin, Centella assiatica and Citrus sinensis have been reported for the synthesis of SNP (Logeswari et al., 2015). The plant extracts were reported to act as reducing and capping agents, thereby reducing the silver ions $\left(\mathrm{Ag}^{+}\right)$to metallic silver $\left(\mathrm{Ag}^{\circ}\right)$.

In the present study, Irenopsis, Diaporthe and Sphaerosporium spp. were the fungi isolated from diseased tomato. Although, Koch Postulate was not tested, the association of these pathogens with the diseased tomato plant may be implicated to contribute to the symptoms observed, because there are several reports on their pathogenicity. Irenopsis sp. has been known to cause black mildew in crop plants (Piepenbring, 2015). Species of the genus, Diaporthe is made up of diverse species ranging from saprophytic, endophytic to parasitic organisms (Gomes et al., 2013). An example of a pathogenic Diaporthe sp. is D. citri (Gopal et al., 2014).

The antifungal properties of CPE, SNS and SNP were investigated on the test organisms. The results obtained indicated that CPE did not offer any antifungal activity 
Table 2. Effects of Citrus peel extract, silver nitrate solution and silver nanoparticles on the mycelial growth of Diaporthe species

\begin{tabular}{|c|c|c|c|c|c|c|c|c|c|c|c|c|}
\hline \multirow{2}{*}{$\begin{array}{l}\text { Conc. } \\
\text { (\%) }\end{array}$} & \multicolumn{3}{|c|}{2 days } & \multicolumn{3}{|c|}{4 days } & \multicolumn{3}{|c|}{6 days } & \multicolumn{3}{|c|}{8 days } \\
\hline & CPE (cm) & SNS (cm) & SNP (cm) & CPE (cm) & SNS (cm) & SNP (cm) & CPE (cm) & SNS (cm) & SNP (cm) & CPE (cm) & SNS (cm) & SNP (cm) \\
\hline 0 & & & & & & & & & & & & 0.55 \\
\hline 50 & $2.40^{\mathrm{ab} \pm 0.00}$ & $2.40^{\mathrm{c} \pm}$ & 1.15 & 00 & 3.3 & 1. & 50 & 3.25 & 2.2 & 3.70 & .40 & .85 \\
\hline 100 & $2.55^{\mathrm{b}} \pm 0.05$ & $2.00 \mathrm{a} \pm 0.00$ & $1.15^{\mathrm{a} \pm 0.05}$ & $3.35^{b} \pm 0.05$ & $2.95^{\mathrm{a} \pm 0.05}$ & $1.35^{\mathrm{a} \pm 0.05}$ & $4.05^{\mathrm{a} \pm 0.15}$ & $3.15^{\mathrm{a} \pm 0.05}$ & $1.75^{\mathrm{c}} \pm 0.05$ & $4.45^{a} \pm 0.55$ & $3.30^{\mathrm{a}} \pm 0.20$ & $1.80^{\mathrm{a} \pm 0.00}$ \\
\hline
\end{tabular}

Values are presented as means \pm standard errors. Figures bearing similar superscripts within the same columns are not significantly different using Duncan's Multiple Range (DMR) test at 0.05 level of significance. CPE: Citrus peel extract; SNS: Silver nitrate solution; SNP: Silver nanoparticles
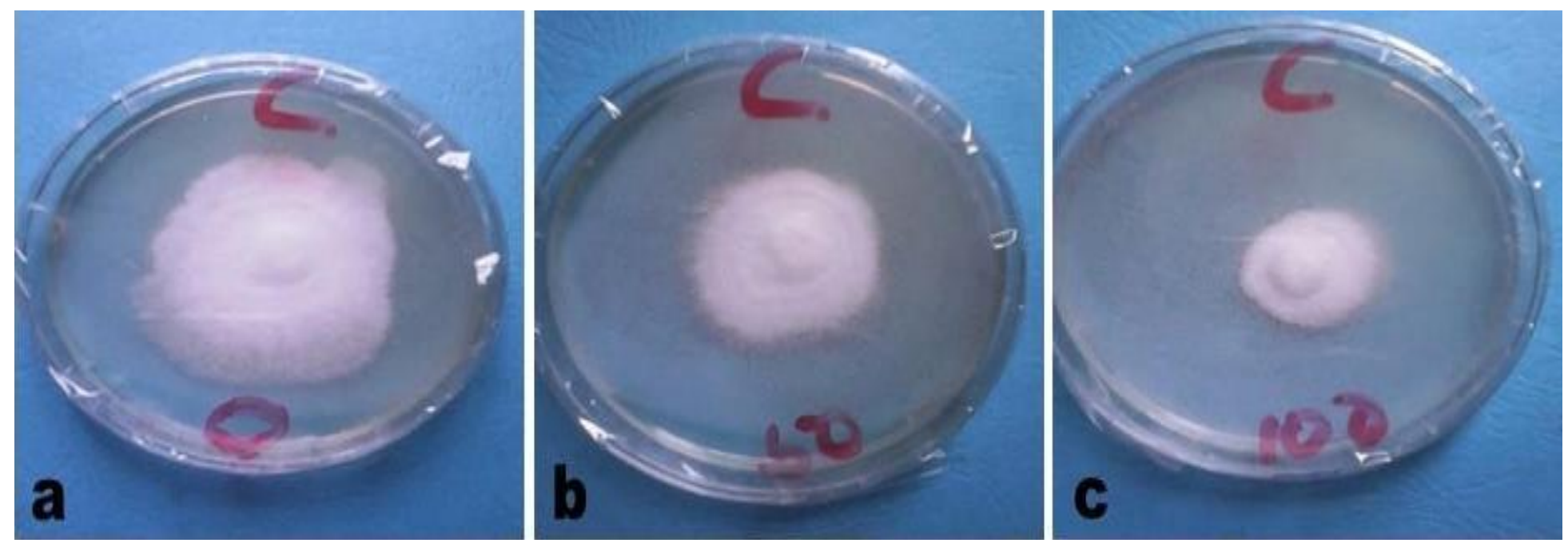

Figure 5: Effects of silver nanoparticle on the mycelia growth of Diaporthe sp. grown on PDA at room temperature after 6 days of incubation. a: Control ( $0 \%$ concentration of silver nanoparticles); b: $50 \%$ silver nanoparticles; c: $100 \%$ silver nanoparticles

Table 3. Effects of Citrus peel extract, silver nitrate solution and silver nanoparticles on the mycelial growth of Sphaerosporium species

\begin{tabular}{|c|c|c|c|c|c|c|c|c|c|c|c|c|}
\hline \multirow{2}{*}{$\begin{array}{l}\text { Conc. } \\
(\%)\end{array}$} & \multicolumn{3}{|c|}{2 days } & \multicolumn{3}{|c|}{4 days } & \multicolumn{3}{|c|}{6 days } & \multicolumn{3}{|c|}{8 days } \\
\hline & CPE (cm) & SNS (cm) & SNP (cm) & CPE (cm) & SNS (cm) & SNP (cm) & CPE (cm) & SNS (cm) & SNP (cm) & CPE (cm) & SNS (cm) & SNP (cm) \\
\hline 0 & $1.40 \mathrm{a} \pm 0.20$ & $1.50 \mathrm{a} \pm 0.10$ & $1.45^{\mathrm{a} \pm 0.15}$ & $2.35^{\mathrm{a} \pm 0.05}$ & $2.45^{\mathrm{a} \pm 0.05}$ & $2.15^{\mathrm{a} \pm 0.25}$ & $2.80 \mathrm{a} \pm 0.30$ & $3.00^{\mathrm{b}} \pm 0.10$ & $2.25^{\mathrm{a}} \pm 0.25$ & $3.90 \mathrm{a} \pm 0.30$ & $4.05^{a} \pm 0.85$ & $4.25^{c} \pm 0.25$ \\
\hline 50 & $1.80 \mathrm{a} \pm 0.10$ & $1.80 \mathrm{a} \pm 0.10$ & $1.20 \mathrm{a} \pm 0.30$ & $2.40^{\mathrm{a}} \pm 0.30$ & $2.30 \mathrm{a} \pm 0.20$ & $1.85^{\mathrm{a}} \pm 0.35$ & $3.05 \mathrm{a} \pm 0.05$ & $2.85^{b} \pm 0.05$ & $2.20 \mathrm{a} \pm 0.80$ & $3.06 \mathrm{a} \pm 0.04$ & $3.05^{\mathrm{a}} \pm 0.05$ & $2.50^{\mathrm{b}} \pm 0.00$ \\
\hline 100 & $1.90 \mathrm{a} \pm 0.00$ & $1.75 \mathrm{a} \pm 0.15$ & $1.20 \mathrm{a} \pm 0.10$ & $2.80^{\mathrm{a}} \pm 0.00$ & $2.25^{\mathrm{a}} \pm 0.05$ & $1.70 \mathrm{a} \pm 0.20$ & $3.05^{\mathrm{a}} \pm 0.55$ & $2.50 \mathrm{a} \pm 0.00$ & $2.20 \mathrm{a} \pm 0.40$ & $3.08 \mathrm{a} \pm 0.52$ & $2.58 \mathrm{a} \pm 0.02$ & $1.75^{\mathrm{a} \pm 0.05}$ \\
\hline
\end{tabular}

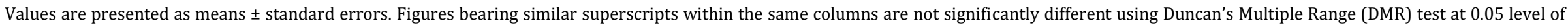
significance. CPE: Citrus peel extract; SNS: Silver nitrate solution; SNP: Silver nanoparticles. 

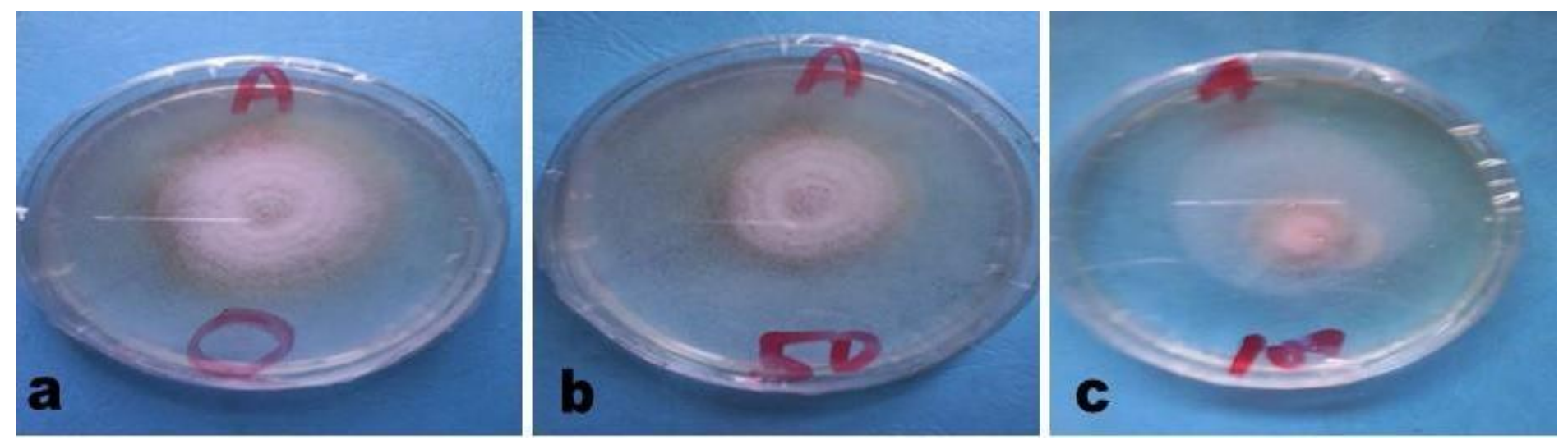

Figure 6: Effects of silver nanoparticle on the mycelia growth of Sphaerosporium sp. grown on PDA at room temperature after 6 days of culture. a: Control ( $0 \%$ concentration of silver nanoparticles); b: $50 \%$ silver nanoparticles; c: $100 \%$ silver nanoparticles

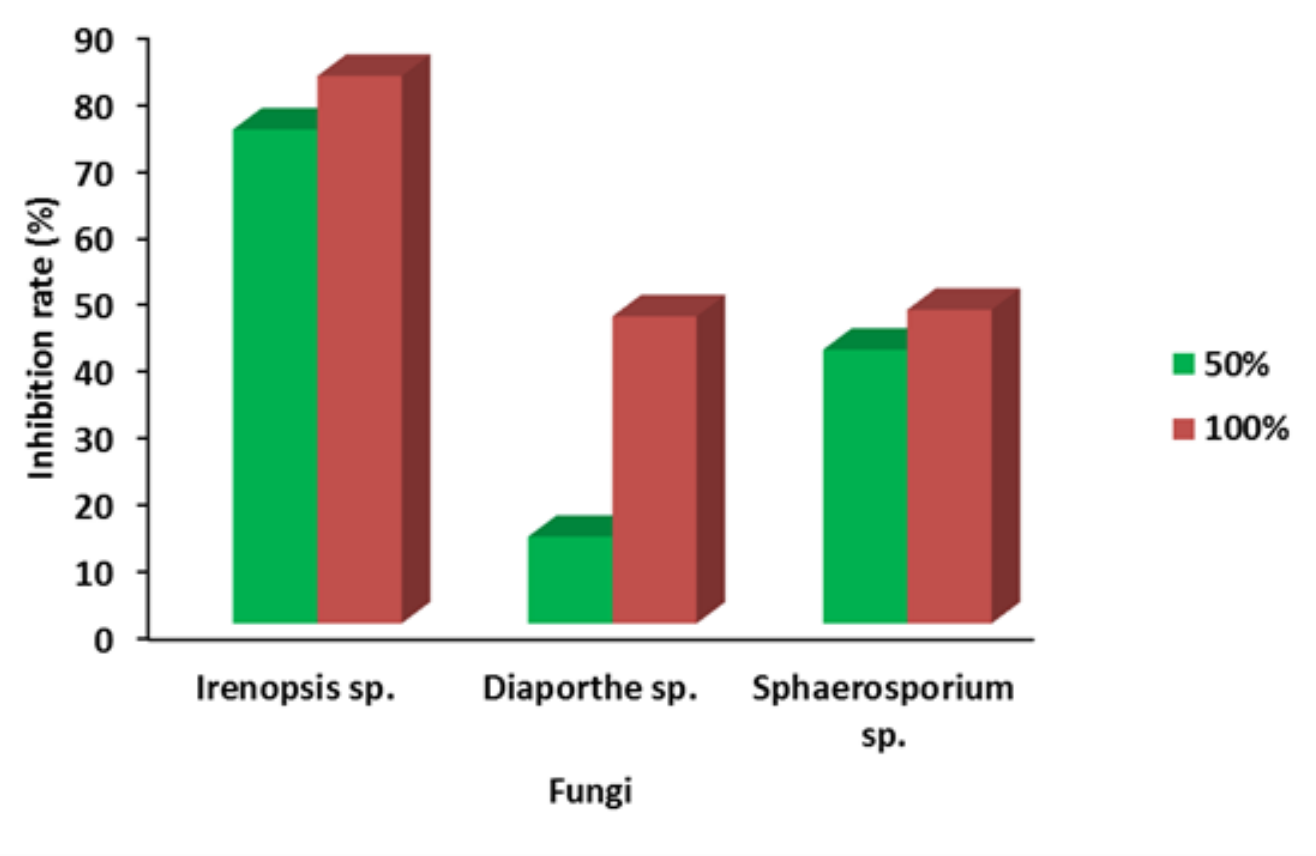

Figure 7: Inhibition rate of 50 and $100 \%$ silver nanoparticles on the mycelia growth of test pathogens after 8 days of culture initiation

against the test organisms. However, oil extract from orange peels has been reported to control certain pathogens such as Aeromonas hydrophila and Klebsiella pneumonia (Al-saad et al., 2009). Unlike CPE, SNS offered a basal antifungal activity against the test pathogens. There was a significant $(\mathrm{p}<0.05)$ difference in the mycelia growth of Irenopsis sp. when the pathogen was subjected to $0 \%$ (control) and $100 \%$ concentration of SNS at day 8 of incubation (Table 1). This observation agrees with previous studies on the antimicrobial activity of silver ions on phytopathogenic fungi as reported by Jo et al. (2009). Unlike CPE and SNS, SNP significantly inhibited the mycelia growth of test fungal pathogens. Post hoc analysis using the Duncan multiple range test showed that there was a significant difference (at 0.05 level of significance) in the mycelia growth of Irenopsis sp. subjected to different concentrations of silver nanoparticles treatment, including, 0,50 and $100 \%$. This showed that the antifungal activity observed in this study was due to the silver nanoparticles treatment and not the extract that was used for the synthesis. Although, silver nitrate solution offered a basal level of protection in this study, but it was negligible compared to silver nanoparticles. It can therefore be hypothesized that the antimicrobial activity of silver ions is 
increased when broken down to nanoparticle state. This observation agrees with previous studies that have reported antimicrobial activity of silver nanoparticles (Balakumaran et al., 2016; Logeswari et al., 2015; Kumarasamyraja and Jganathan, 2013; and Suna et al., 2014). However, this is the first report showing the antimicrobial activity of silver nanoparticles against Irenopsis sp. The mechanisms underlying the antimicrobial property of silver nanoparticle is still a hotly debated topic that is yet to be well elucidated. However, silver nanoparticles have been reported to cause the deactivation of enzymes by binding to thiol groups, thus forming a stable S-Ag bond (Ahmed et al., 2016). The formation of free radicals by silver nanoparticles may also be responsible for its antimicrobial properties (Panigrahi, 2013). Silver nanoparticles have also been reported to act on sulphur and phosphorus components of the DNA, thus destroying it (Morones et al., 2005). This destruction of the DNA would definitely lead to cell death and toxicity in humans

In the same manner, the results obtained on the antifungal activities of SNS against Diaporthe sp. suggested that the silver ions offered a negligible antifungal activity against the test pathogen, even at $100 \%$ concentration while SNP significantly reduced the growth of the organism. This observation of SNP agrees with previous studies that have reported antimicrobial activity of silver nanoparticles (Balakumaran et al., 2016; Logeswari et al., 2015; Kumarasamyraja and Jganathan, 2013; and Suna et al., 2014). Similar observations were also recorded for Sphaerosporium sp. with negligible antifungal activity given by SNS treatment, while CPE did not offer any antifungal activity, but SNP were effective in the control of Sphaerospirium sp. (Table 3).

The inhibition rate of 50 and $100 \%$ silver nanoparticles (Figure 7) showed that $100 \%$ SNP was most effective against Irenopsis sp. (82\% inhibition) compared to Diaporthe sp. (46\% inhibition) and Sphaerosporium sp. (57\% inhibition). These differences in inhibition could be attributed to the differences in the test organisms. Irenopsis $\mathrm{sp}$. is a fast growing organism compared to the other two organisms (Peipenbring, 2015). However, the mode of action of SNP against fungal pathogens should be further investigated.

\section{CONCLUSION}

The results obtained from the study suggested that silver nanoparticles were effective in controlling fungal isolates while Citrus sinensis peel extract did not offer any antimicrobial activity against the test pathogens. There was a basal antifungal activity associated with the inclusion of silver nitrate solution in the culture medium. Further studies should be carried out to elucidate the mode of action of silver nanoparticles in bringing about antimicrobial effects and also how these nanoparticles could be used for managing phytopathogens in order to reduce crop loss, thereby ensuring food security.

\section{Conflict of Interests}

The authors declare that there is no conflict of interests regarding the publication of the paper.

\section{REFERENCES}

Agrios GN (2005). Plant Pathology. Fifth Edition. Elsevier Academic Press, London, 922p.

Ahmed S, Ahmed M, Swami BL, Ikram S (2016). A review on plant extract mediated synthesis of silver nanoparticles for antimicrobial applications: A green expertize. J. Advan. Res., 7: 17 - 28.

Al-saadi NHM, Ahmad NS, Sa'eed, SE (2009). Determination of some chemical compounds and the effect of oil extract from orange peels. J. Kerb. Univ., 7(2): 33 - 39.

Balakumaran MD, Ramachandran R, Balashanmugam P, Mukeshkumar DJ, Kalaichelvan PT (2016). Mycosynthesis of silver and gold nanoparticles: Optimization, characteristics and antimicrobial activity against human pathogens. Microb. Res., 182: 8 - 20.

Godfray HCF, Beddington JR, Crute LR, Haddad L, Lawrence D, Muir JF, Pretty J, Robinson S, Thomas SM,. Toulmin C (2010). Food security: The challenge of feeding 9 billion people. Sci., 327: 812 - 818.

Gomes RR, Glienke C, Videira SIR, Lombard L (2013). Diaporthe: A genus of endophytic, saprobic and plant pathogenic fungi. Persoonia 31: 1- 41 .

Gopal K, Lakshima LM, Sarada G, Nagalakshim T, Sankar TG, Gopi V, Ramana TTV (2014). Citrus melanose (Diaporthe citri Wolf): A review. Intern. J. Curr. Microb. App. Sc. 3(4): $113-124$.

Heuvelink EP (2005). Tomato. Crop production science in horticulture. CABI publishers International, Wallingford, UK. 399p.

Holt JG, Krieg NR, Sneath PHA, Staley JT, Williams ST (1994). Bergey's Manual of Determinative Bacteriology. Ninth edition. Lippincolt Williams and Wilkins, Philadelphia. 787p.

Jo YK, Kim BH, Junk G (2009). Antifungal activity of silver ions and nanoparticles on phytopathogenic fungi. Plant Dis., 93(10): 1037 - 1043.

Kaviya S, Santhanalakshmi J, Viswanathan B, Muthumary J, Srinivasan K (2011). Biosynthesis of silver nanoparticles using Citrus peel extract and its antibacterial activity. Spectroch. Acta Part A: Molec. Biomolec. Spect., 79: 594 598.

Kimura S, Sinha N (2008). Tomato (Solanum lycopersicum): A model fruit-bearing crop. C. Sp. Harb. Prot., 3(11): 1 - 9.

Kumarasamyraja D, Jeganathan NS (2013). Green synthesis of silver nanoparticles using aqueous extract of acalypha indica and its antimicrobial activity. Int. J. Pharm. Biol. Sc., 4(3): 469-76.

Logeswari P, Silambarasan S, Abraham J (2015). Synthesis of silver nanoparticles using plant extracts and analysis of their antimicrobial property. J. Saudi Chem. Soc., 19: 311 $-317$. 
Mahdizadeh V, Safaie N, Khelghatibana F (2015). Evaluation of antifungal activity of silver nanoparticles against some phytopathogenic fungi and Trichoderma harzianum. J. Crop Prot., 4(3): 291 - 300.

Mariselvam R, Ranjiitsingh AJH, Nanthim AUR, Kalirajan K, Padmalatha,C, Selvakumar PM (2014). Green synthesis of silver nanoparticles from the extract of the inflorescence of Cocos nucifera (family: Aracaceae) for enhanced antibacterial activity. Spectroch. Acta Part A: Molec. Biomolec. Spect., 129: 537 - 541.

Morones J, Elechiguerra JL, Camacho A, Holt K, Kouri JB, Ramirez JT, Yacaman MJ (2005). The bactericidal effect of silver nanoparticles. Nanotec., 16: 2346 - 2353.

Panigrahi T (2013). Synthesis and characterization of silver nanoparticles using leaf extract of Azadirachta indica. A thesis submitted in partial fulfilment of the requirements for the degree of Master of Science. Department of Life Sciences, National institute of Technology, Rourkela, India. 70p.

Peipenbring M (2015). Introduction to Mycology in the Tropics. The American Phytopathological Society Printing Press, U.S.A. p. 210-220.

Rao KJ, Paria S (2013). Use of sulphur nanoparticles as green pesticide on Fusarium solani and Venturia inaequalis. RSC Advan., 3: 10471 - 10478.

Savary S, Ficke A, Aubert J, Hollier C (2012). Crop losses due todiseases and their implications for global food production losses and food security. Food Sec., 4: 519 537.

Shittu HO, Robb EJ (2011). Tomato displays characteristics of a model organism for genetic analysis. Nig. J. Life Sc., 1(1): $18-27$.

Suna Q, Cai X, Li J, Zheng M, Chenb Z, Yu CP (2014). Green synthesis of silver nanoparticles using tea leaf extract and evaluation of their stability and antibacterial activity. Col. Surf A: Physicochem Eng Asp., 444: 226 - 231. 